\title{
Study of low vitamin D among children with anorexia in Sulaymaniyah, Kurdistan region, Iraq during summer months
}

Riyadh A. Al-Obeidi, DCh, CABP, Aws H. Al-Numan, FIBMS, MRCPCH.

$$
\begin{aligned}
& \text { ABSTRACT } \\
& \text { الأهداف : تتناول دراستنا تقييم دور نقص فيتامين ( د ) في فقدان }
\end{aligned}
$$

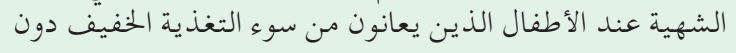

$$
\begin{aligned}
& \text { سبب واضح. } \\
& \text { المنهجية: أجريت هذه الدراسة في مدينة فاروق الطبية في }
\end{aligned}
$$

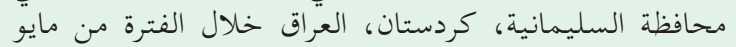

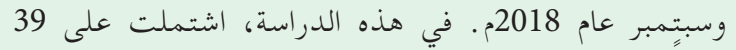

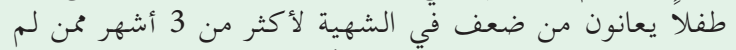

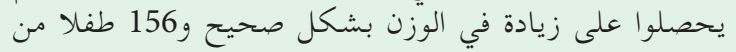

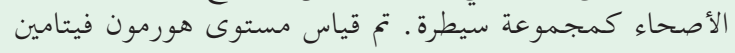

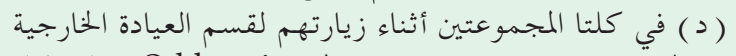

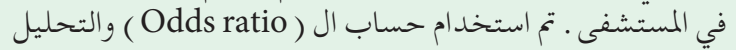

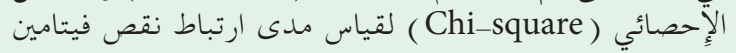

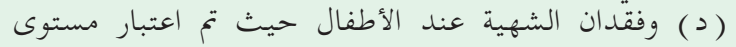

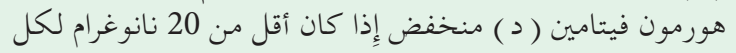

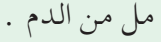

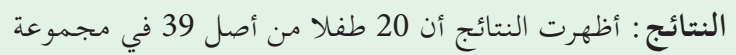

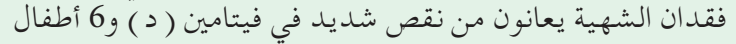

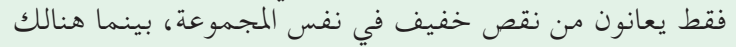

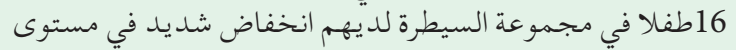

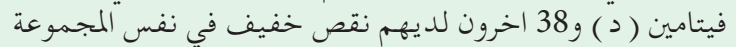

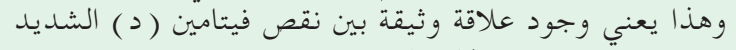

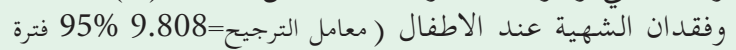

$$
\begin{aligned}
& \text { الثقة (4.089 - 23.523) } \\
& \text { أي علاقة بين النقص الخفيف لفيتامين (د) مل مع فقدان الشهية }
\end{aligned}
$$

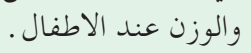

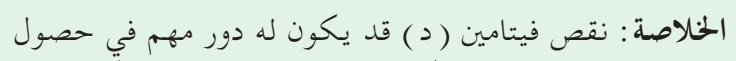

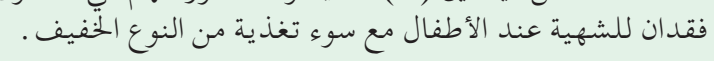

Objectives: To determine the impact of vitamin D deficiency and insufficiency on the development of anorexia in children with mild malnutrition without an obvious cause.
Methods: This cross-sectional study was conducted in Faruk Medical City, Sulaymaniyah, Kurdistan Region, Iraq, between May and September 2018. It included 39 mildly malnourished children with a poor appetite for over 3 months and 156 children who were healthy except for minor illnesses as the control group. All the children were regular attendees at the outpatient clinic and were tested for serum levels of 25-hydroxy vitamin $\mathrm{D}$. We used binary logistic regression statistical analysis to measure the significance of the association between vitamin D deficiency/insufficiency and anorexia with mild malnutrition in young children.

Results: Of the 39 children in the anorexia group, 20 had vitamin D deficiency, and the remaining 6 had vitamin $\mathrm{D}$ insufficiency. On the other hand, 16 of the remaining children with normal appetites, showed a vitamin D deficiency, and 38 of them displayed insufficiency. Statistically significant association between vitamin $\mathrm{D}$ deficiency and anorexia with malnutrition was noted (odd ratio: 9.808; 95\% confidence interval: $4.089-23.523 ; p=0.0001$ ), while it was insignificant with vitamin $\mathrm{D}$ insufficiency.

Conclusion: This study displayed a noteworthy relationship between vitamin D deficiency and anorexia with mild malnutrition in young children.

Saudi Med J 2019; Vol. 40 (11): 1129-1133 doi: $10.15537 /$ smj.2019.11.24598

From the Department of Pediatric (Al-Obeidi), College of Medicine and from the Faruk Medical City (Al-Numan), Sulaymaniyah, Kurdistan Region, University of Mosul, Mosul, Iraq.

Received 30th April 2019. Accepted 24th September 2019.

Address correspondence and reprint request to: Dr. Aws H. Al-Numan, Department of Pediatric, College of Medicine, University of Mosul, Mosul, Iraq. E-mail: awshazimah72@uomosul.edu.iq ORCID ID: https://orcid.org/0000-0001-6933-8366 
A norexia is a designate for poor appetite of all kinds of food. It is characterized by a decrease in the desire to eat and can be caused by any illness. In a curable disease, the appetite should improve once the underlying cause is resolved. Anorexia is prevalent among children. Short-term illnesses in children can cause temporary loss of appetite without loss of weight. However, protracted loss of appetite is associated with inadequate weight gain, which may be due to various underlying serious conditions or behavioral (non-organic) causes. ${ }^{1}$ Vitamin D is a secosteroid, that plays an essential function in calcium homeostasis and has multiple other biological effects in the body. ${ }^{2}$ It is considered a hormone which acts via nuclear receptors present in multiple organs such as the bone, brain, intestine, kidneys, immune system, and most other body parts. ${ }^{3}$ The skin is considered as the main source of vitamin D supply following the exposure to the sun's ultraviolet radiation. ${ }^{4}$ Vitamin D deficiency is pandemic and remains underdiagnosed and undertreated worldwide. It most commonly results from inadequate sun exposure, malabsorption, or problems related to the kidney and liver. ${ }^{5}$ Deficiency of vitamin D is the main etiology of rickets in children, and osteomalacia in adults. ${ }^{6}$ Extensive study has suggested that vitamin $\mathrm{D}$ deficiency might be responsible for the increase in the risk of the development of numerous illnesses such as asthma, diabetes mellitus, cardiovascular problems, immune defects, infections as well as cancer, which can be treated with the regular intake of vitamin $\mathrm{D}$ in physiological doses or by correction of its deficiency., 5,7 Previous study reported ${ }^{8}$ that vitamin $\mathrm{D}$ deficiency is pervasive among adolescents who suffer from anorexia nervosa and bulimia nervosa. Also, it has been noticed that obese children are more liable to be deficient in vitamin D.?

In this study, we aimed to determine the relationship between vitamin $\mathrm{D}$ deficiency/insufficiency and the development of anorexia, which causes mild malnutrition in young children.

Methods. This cross-sectional study was conducted in Faruk Medical City, Sulaymaniyah, Kurdistan Region, Iraq. To avoid the seasonal changes in the vitamin D

Disclosure. Authors have no conflict of interests, and the work was not supported or funded by any drug company. levels, ${ }^{10,11}$ the data were collected prospectively during the summer months between May and September 2018. We received written informed consent from the parents of the enrolled children. The Medical Research Ethics Committee of the College of Medicine, University of Mosul, Iraq approved the study, which is consistent with the principles of the Helsinki Declaration.

In this study, we included children aged 2-6 years who visited our outpatient department, and were suffering from anorexia for over 3 months along with mild malnutrition but had no underlying serious or chronic illnesses. Children with anemia, underlying chronic illnesses, a picky eating which is a commonly encountered habit in children with a tendency to food selection, as well as diet neophobia which does not result in malnutrition, were excluded from the study. ${ }^{12}$

Since we had multiple data points for each child, the level of nutrition was diagnosed based on the deceleration of the child's Z-score for weight-for-height. A Z-score decline of one was considered as mild malnutrition based on the American Society for Parenteral and Enteral Nutrition consensus statement on pediatric malnutrition. ${ }^{13}$ The children enrolled in this study were divided into 2 groups (anorexia with mild malnutrition group and, a normal appetite group). All these cases were registered, and had medical records in the hospital, which indicated that their previous $\mathrm{Z}$-scores ranged from 0 and -0.9. In addition to a thorough physical examination, detailed nutritional, birth, family, and social histories were collected from each participant in the study. For subjects with malnutrition in the anorexia group, further tests including, complete blood count, urinalysis, and other clinically directed blood tests such as iron profile, celiac screening, thyroid function tests, and other radiological investigations, were performed to rule out any possible underlying illnesses that may be responsible for anorexia and mild malnutrition.

Both groups were tested for 25-hydroxyvitamin D serum levels. Given that the normal range for 25-hydroxyvitamin $\mathrm{D}$ in healthy subjects is $20-50 \mathrm{ng} / \mathrm{ml}$, a cut-off value of $20 \mathrm{ng} / \mathrm{ml}$ was chosen based on the recommendations of the 2016 Global Consensus. Levels between 12-20 ng/ml indicated vitamin D insufficiency, and those below $12 \mathrm{ng} / \mathrm{ml}$ indicated vitamin D deficiency. ${ }^{10,11}$

The Google Scholar search engine and the PubMed electronic database have been used to find prior related researches using keywords like vitamin D deficiency, anorexia, malnutrition, and leptin.

Cobas e 411 analyzer (Roche Diagnostics GmbH, Mannheim, Germany) was used for the measurement of 25-hydroxyvitamin D (Elecsys ${ }^{\odot}$ Vitamin D total), ferritin 
(Elecsys ${ }^{\oplus}$ Ferritin, Roche Diagnostics International.) and thyroid function tests (The Elecsys TSH, Elecsys ${ }^{\circ}$ T4). Swelab Alfa Plus hematology analyzer (Spånga, Sweden) was used for the determination of complete blood count, and Chorus Elisa kits (Diesse Diagnostica Senese Spa, Monteriggioni, Italy) were used for the celiac screen (CHORUS TTG-A).

Statistical analysis. To evaluate the role of vitamin D deficiency/insufficiency in the occurrence of anorexia with poor weight gain, we used binary logistic regression analysis, in which the data of cases with anorexia and malnutrition were considered as the dependent variable (we implemented 1.0 as a binary model for the analysis of values of cases with anorexia and malnutrition), and 3 independent variables (predictors) according to vitamin $\mathrm{D}$ serum levels (normal, insufficient as well as vitamin $\mathrm{D}$ deficient values). We calculated the odds ratio as well as the confidence interval for each association. Significance was determined using the Chi-square test (with one-degree freedom), and a $p$-value of less than 0.05 was considered to be significant. All statistical analyses were performed using IBM SPSS Statistics for Windows, version 23 (IBM Corp, Armonk, NY, USA). ${ }^{14}$

Results. We enrolled a total number of 195 children, of which 39 (mean age: 50.3 \pm 14.3 months) had anorexia and mild malnutrition (anorexia group). The remaining children (mean age: $48.98 \pm 15.2$ months) formed the normal appetite group (Table 1). While more than half of the subjects in the anorexia group had vitamin $\mathrm{D}$ deficiency, a small proportion of them had vitamin $\mathrm{D}$ insufficiency. The majority of the children in the normal appetite group had normal vitamin D levels (Figure 1). Our results revealed a significant association between vitamin $\mathrm{D}$ deficiency and loss of appetite with mild malnutrition in children aged 2-6 years, whereas vitamin D insufficiency showed no significant association (Table 2). Mean vitamin D levels shown in Table 3 indicate that girls were predominant among children with vitamin D deficiency/insufficiency in both groups.
Discussion. Vitamin D is a key element required for maintaining good health. ${ }^{15}$ Our study shows a significant association between vitamin D levels and anorexia, which could, in turn, contribute to mild malnutrition seen in children aged 2-6 years. Our results are in line with the report published by Combs et al, ${ }^{16}$ which showed that loss of appetite is a symptom of vitamin D deficiency. Another study by Maetani et $\mathrm{al}^{17}$ has described an inverse relationship between levels of vitamin D and leptin hormone (also known as the anorexigenic hormone). Underlying this inverse relationship is the $\mathrm{D}$ - mediated inhibition of leptin hormone, which could account for the decrease in appetite and weight loss in vitamin $\mathrm{D}$ deficient subjects. ${ }^{17}$ Hajimohammadi et al $^{18}$ also suggested a similar relationship between levels of vitamin D and leptin hormone in his meta-analysis of several observational studies. Many studies in adolescents have reported a significant association between vitamin $\mathrm{D}$ deficiency and eating disorders like anorexia nervosa and its sequel..$^{8,19}$ However, the findings on vitamin D

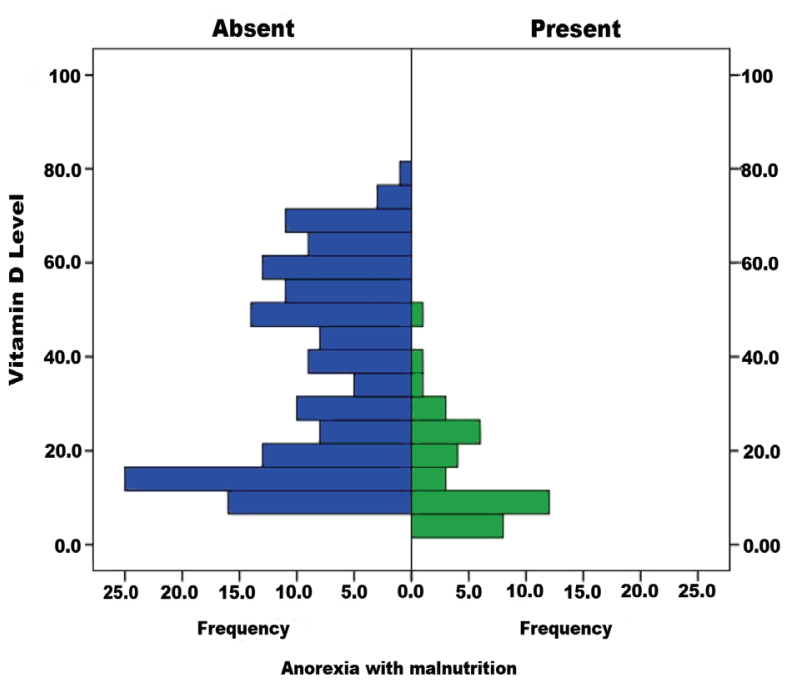

Figure 1 - Relationship of vitamin D levels with the development of anorexia and malnutrition.

Table 1 - Distribution of subjects based on gender and vitamin D levels $(\mathrm{N}=195)$.

\begin{tabular}{lrrrrrr}
\hline Vitamin D & \multicolumn{3}{c}{ Anorexia group $(\mathbf{n}=39)$} & \multicolumn{3}{c}{ Normal appetite group $(\mathbf{n}=156)$} \\
level $(\mathbf{n g} / \mathrm{ml})$ & Boys & \multicolumn{1}{c}{ Girls } & \multicolumn{1}{c}{ Total } & \multicolumn{1}{c}{ Boys } & \multicolumn{1}{c}{ Girls } & \multicolumn{1}{c}{ Total } \\
\hline$<12$ & $7(35.0)$ & $13(65.0)$ & $20(51.3)$ & $4(25.0)$ & $12(75.0)$ & $16(10.3)$ \\
$12-20$ & $2(33.3)$ & $4(66.7)$ & $6(15.4)$ & $12(31.6)$ & $26(68.4)$ & $38(24.4)$ \\
$\geq 20$ & $8(1.5)$ & $5(38.5)$ & $13(33.3)$ & $52(60.0)$ & $50(49.0)$ & $102(65.4)$ \\
\hline \multicolumn{6}{c}{ Values are presented as numbers and percentage (\%). } \\
\hline
\end{tabular}


Table 2 - Statistical analysis using logistic regression showing the significance of association of low vitamin D levels with anorexia.

\begin{tabular}{lccccccc}
\hline $\begin{array}{l}\text { Status of vitamin } \\
\text { D level }\end{array}$ & B & S.E & Wald & Df & Sig. & Exp(B) & $\begin{array}{c}\text { 95\% CI for Exp(B) } \\
\text { Lower }\end{array}$ \\
\hline Ueficiency & 2.283 & 0.446 & 26.165 & 1 & 0.000 & 9.808 & 4.089 \\
Insufficiency & 0.214 & 0.529 & 0.164 & 1 & 0.685 & 1.239 & 0.439 \\
Constant & -2.060 & 0.294 & 48.932 & 1 & 0.000 & 0.127 & 3.493 \\
\hline \multicolumn{2}{r}{ B - coefficient for constance, S.E - standard error, Exp(B) - odd ratio, Sig - $p$-value, Df - degree of freedom, Wald - Chi-square, } \\
\hline
\end{tabular}

Table 3 - Vitamin D levels in the anorexia and normal appetite groups.

\begin{tabular}{lcccc}
\hline $\begin{array}{l}\text { Vitamin D } \\
\text { level }(\mathbf{n g} / \mathrm{ml})\end{array}$ & \multicolumn{2}{c}{ Anorexia group } & \multicolumn{2}{c}{ Normal appetite group } \\
& Boys & Girls & Boys & Girls \\
\hline$<12$ & $7.4 \pm 2.13$ & $6.5 \pm 2.2$ & $9.5 \pm 1.11$ & $8.4 \pm 1.4$ \\
$12-20$ & $15.8 \pm 2.03$ & $13.5 \pm 2.1$ & $16 \pm 1.98$ & $15 \pm 2.6$ \\
$\geq 20$ & $28.6 \pm 8.01$ & $25.3 \pm 4.9$ & $43 \pm 12.06$ & $39.6 \pm 14.2$ \\
\hline
\end{tabular}

and eating disorders have been conflicting. Horlick ${ }^{20}$ has reported that vitamin D deficiency interferes with the secretion of the appetite-suppressing hormone, leptin, leading to an increase in appetite. ${ }^{20}$ Other studies have also shown that obese children are more prone to vitamin $\mathrm{D}$ deficiency. ${ }^{9,21}$ Additionally, the role of vitamin $\mathrm{D}$ in the loss of both appetite and weight has been demonstrated in conditions of vitamin D toxicity. ${ }^{22}$

Our study also highlighted the differences in the effects of vitamin D levels on anorexia based on gender. Most of the children with vitamin D deficiency and insufficiency in the anorexia and control groups were girls, which can be explained by the type of clothing they wear, covering most of their body. Moreover, compared to boys, girls spend less time playing outdoors, thereby reducing their sun exposure, which is essential for vitamin D synthesis. A study of vitamin $D$ in children of school age in Saudi Arabia has also revealed that girls are more liable to have vitamin $\mathrm{D}$ deficiency when compared to boys. ${ }^{23}$

Study limitations. First is the small sample size, which was due to the short study period to avoid seasonal variations in the levels of vitamin D. Second, despite the efforts to exclude subjects with underlying chronic diseases that cause anorexia and poor weight gain, the possibility of having included such children cannot be totally ruled out. Third, the study does not test the association between vitamin D deficiency and the other more severe forms of malnutrition. Fourth, there is no follow-up so the causality is limited. Finally, although we tried to exclude toddlers with unclear picky eating behaviors, the unintended inclusion of such children could have influenced the results.
In conclusion, the role of vitamin D deficiency in the emergence of anorexia with mild malnutrition among young children, which could be added as a new finding to what is already known of its relation with eating disorders in adolescents. Our findings reveal a significant association between vitamin D deficiency and anorexia with poor weight gain in children, thereby suggesting that vitamin D deficiency might be the consequence of anorexia, or it could be a factor contributing to anorexia in children younger than 6 years of age.

Further studies are recommended to validate our findings and to determine if vitamin D supplements or therapeutic correction of vitamin D deficiency can help lower the risk of anorexia as well as resolve the eating disorders in children.

Acknowledgment. We would like to thank Editage (www.editage.com) for the English language editing.

\section{References}

1. McGreal N, Ulshen MH. Loss of Appetite. In: McInerny TK, Adam HM, Campbell DE, DeWitt TG, Foy JM, Kamat DM, editors. American Academy of Pediatrics Textbook of Pediatric Care. 2nd ed. Elk Grove Village (IL): American Academy of Pediatrics; 2017. p. 1497-1499.

2. Chawes B, Bønnelykke K, Bisgaard H. Prenatal vitamin D supplementation to improve health in offspring. JAMA Pediatr 2018; 172: 617-618.

3. Bikle D. Vitamin D: production, metabolism, and mechanisms of action. In: Feingold KR, Anawalt B, Boyce A, et al., editors. Endotext [Internet]. South Dartmouth (MA): MDText.com, Inc.; 2000.

4. Holick MF. Biological effects of sunlight, ultraviolet radiation, visible light, infrared radiation and vitamin $\mathrm{D}$ for health. Anticancer Res 2016; 36: 1345-1356.

5. Holick MF. The vitamin D deficiency pandemic: Approaches for diagnosis, treatment and prevention. Rev Endocr Metab Disord 2017; 18:153-165.

6. Creo AL, Thacher TD, Pettifor JM, Strand MA, Fischer PR. Nutritional rickets around the word: an update. Paediatr Int Child Health 2017; 37: 84-98.

7. Wang H, Chen W, Li D, Yin X, Zhang X, Olsen N, et al. Vitamin D and chronic diseases. Aging Dis 2017; 8: 346-353.

8. Modan-Moses D, Levy-shraga Y, Pinhas-Hamiel O, Kochavi B, Enoch-Levy A, Vered I et al. High prevalence of vitamin D deficiency and insufficiency in adolescent inpatients diagnosed with eating disorders. Int J Eat Discod 2015; 48: 607-614. 
9. Pereira-Santos M, Costa PR, Assis AM, Santos CA, Santos DB. Obesity and vitamin D deficiency: a systematic review and meta-analysis. Obes Rev 2015; 16: 341-349.

10. UpToDate. Vitamin D insufficiency and deficiency in children and adolescents. [Updated 2019. Accessed date 2019 April 20]. Available from: https://www.uptodate.com/ contents/vitamin-d-insufficiency-and-deficiency-in-childrenandadolescents? search=Vitamin\%20D\&source=search_result \&selectedTitle=3 145\&usage_type=default\&display_rank=2.

11. Klingberg E, Oleröd G, Konar J, Hammarsten O. Seasonal variations in serum 25-hydroxy vitamin D levels in a Swedish cohort. Endocrine 2015; 49: 800-808.

12. Lafraire J, Rioux C, Giboreau A, Picard D. Food rejections in children: Cognitive and social/environmental factors involved in food neophobia and picky/fussy eating behavior. Appetite 2016; 96: 347-357.

13. Becker P, Carney LN, Corkins MR, Monczka J, Smith E, Smith SE, et al. Consensus statement of the Academy of Nutrition and Dietetics/American Society for Parenteral and Enteral Nutrition: indicators recommended for the identification and documentation of pediatric malnutrition (undernutrition). Nutr Clin Pract 2015; 30: 147-161.

14. Indrayan A, Malhotra RK. Medical biostatistics. 4th ed. Boca Raton (FL); CRC Press; 2018.

15. Gil Á, Plaza-Diaz J, Mesa MD. Vitamin D: Classic and novel actions. Ann Nutr Metab 2018; 72: 87-95.
16. Combos GF, McClung JP. The Vitamins: Fundamental aspects in nutrition and health. 5th ed. Elsevier; 2017.

17. Maetani M, Maskarinec G, Franke AA, Cooney RV. Association of leptin, 25-hydroxyvitamin D, and parathyroid hormone in women. Nutr Cancer 2009; 61: 225-231.

18. Hajimohammadi M, Shab-Bidar S, Neyestani TR. Vitamin $\mathrm{D}$ and serum leptin: a systematic review and meta-analysis of observational studies and randomized controlled trials. Eur J Clin Nutr 2017; 71: 1144-1153.

19. Gatti D, El Ghoch M, Viapiana O, Ruocco A, Chignola E, Rossini $\mathrm{M}$ et al. Strong relationship between vitamin D status and bone mineral density in anorexia nervosa. Bone 2015; 78 : 212-215.

20. Holick MF. The vitamin D solution, A 3-step strategy to cure our most common health problems. 1st ed. New York: Penguin; 2010. p. 62.

21. Christy B, Hua L, Glenn. Prevalence of vitamin D deficiency among overweight and obese US children. Pediatrics 2013; 113: 152-161.

22. Vogiatzi MG, Jacobson-Dickman E, DeBoer MD. Vitamin $\mathrm{D}$ supplementation and risk of toxicity in pediatrics: a review of current literature. J Clin Endocrinol Metab 2014; 99: 1132-1141.

23. Al-Saleh Y, Al-Daghri NM, Khan N, Alfawaz H, Al-Othman AM, Alokail MS, et al. Vitamin D status in Saudi school children based on knowledge. BMC Pediatr 2015; 15: 53. 